\title{
AVALIAÇÃO DE SUSTENTABILIDADE DE ASSENTAMENTOS RURAIS NO BRASIL: UMA PROPOSTA METODOLÓGICA
}

\author{
Júnio Gregório Roza dos Santos \\ Mestre em Geografia pelo Programa de Pós-Graduação em Geografia - PPGeo da Universidade Federal de \\ Goiás - UFG, Goiânia, GO \\ juniogregorio2011@gmail.com
}

Selma Simões de Castro

Profa Senior da Escola Superior de Agricultura Luiz de Queiroz - ESALQ/USP e colaboradora da Pós Graduação em Geografia do Instituto de Geociências - IGeo/Unicamp

\begin{abstract}
RESUMO
O desenvolvimento sustentável possibilita melhorar as políticas públicas do programa de Reforma Agrária, por contemplar abordagem ampla e multifuncional de desenvolvimento viabilizando sua inserção econômica, ao menos no mercado regional, e uma maior qualidade de vida dos beneficiários, além da conservação de recursos naturais. O objetivo deste artigo é apresentar uma metodologia de avaliação da sustentabilidade de Projetos de Assentamentos (PAs) no país, associando as dimensões da sustentabilidade às Funções de Uso das Terras (FUTs). A metodologia foi testada em dois PAs do estado de Goiás, um no sul e outro no nordeste do estado, socioeconomicamente bem contrastados. Os resultados corroboraram o contraste: o do sul mais próximo da sustentabilidade e do nordeste, ao contrário, bem distante. As causas se encontram na diferente aptidão agrícola, no acesso às técnicas e recursos financeiros para o uso e manejo dos solos e na inserção na economia local e regional, todos maiores e melhores no sul do que no nordeste. Conclui-se que a metodologia é satisfatória e pode ser aplicada em qualquer Projeto de Assentamento agrícola no país.

Palavras-chave: Funções de uso das terras. Indicadores de sustentabilidade. Projetos de assentamentos rurais. Estado de Goiás, Brasil.
\end{abstract}

\section{SUSTAINABILITY ASSESSMENT OF RURAL SETTLEMENTS IN BRAZIL: A METHODOLOGICAL PROPOSAL}

\begin{abstract}
Sustainable development enables improvements in public policies to the Agrarian Reform program, because it contemplates a broad and multifunctional approach to development, enabling economic insertion, at least in the regional market, and a better quality of life for the beneficiaries, in addition to the conservation of natural resources. The aim of this article is to present a methodology for assessing the sustainability of Settlement Projects (PAs) in the country, associating the dimensions of sustainability with Land Use Functions (FUTs). The methodology was tested in two PAs in the state of Goiás, one in the south and the other in the northeast of the state, socioeconomically well contrasted. The results corroborate the contrast: the south closer to sustainability and the northeast, on the contrary, farther away. The causes are found in the different agricultural aptitude, access to techniques and financial resources for the use and management of soils and insertion in the local and regional economy, all greater in the south than in the northeast. It is concluded that the methodology is satisfactory and can be applied in any agricultural settlement project in the country.

Key words: Land use functions. Sustainability indicators. Rural settlement projects. State of Goiás, Brazil.
\end{abstract}




\section{INTRODUÇÃO}

Em meio à intensificação da concentração fundiária e à presença atuante de movimentos sociais reivindicatórios de reforma agrária no País, os governos têm buscado atender essa demanda a partir da implementação de uma política de criação de assentamentos rurais, considerada por muitos como controversa. A sua execução encontra-se a cargo do Instituto de Colonização e Reforma Agrária INCRA, que estabelece como diretrizes fundamentais de suas ações, a democratização do acesso à terra a partir da criação e implantação de projetos de assentamentos (PAs) sustentáveis, buscando contribuir para a capacitação das famílias, o fomento da agroecologia e a qualificação das unidades rurais através de crédito rural, assistência técnica, serviços sociais e infraestrutura e da articulação com outras políticas voltadas à agricultura familiar (INCRA, 2015).

Quanto à qualidade e eficácia das ações dos órgãos responsáveis por sua implementação, as intervenções decorrentes da política de criação de PAs têm sido alvo de uma série de críticas vindas tanto de estudiosos da temática, quanto dos próprios beneficiários. O cerne dessas críticas reside no fato de que as intervenções não têm sido capazes de proporcionarem as condições básicas necessárias para a consolidação de modelos de desenvolvimento que permitam a geração de emprego, de renda e a melhoria na qualidade de vida das famílias assentadas, salvaguardando, ao mesmo tempo, a conservação dos recursos naturais disponíveis, principalmente dos solos, recursos hídricos e da fauna e flora.

A literatura tem destacado que os problemas mais comuns são: a baixa atenção aos critérios de qualidade na seleção de terras para a criação dos PAs, feita com frequência em áreas que apresentam características altamente restritivas à produção (SPAROVECK, 2003; 2005) e/ou até mesmo que já se encontram degradadas por usos anteriores (FERREIRA, 1994); a má gestão dos recursos advindos de crédito rural e a baixa organização comunitária das famílias (ZAMBERLAM, 1994); a ausência de assistência técnica continuada e adaptada às condições produtivas locais e o isolamento dos PAs, associado à baixa integração comercial com o seu entorno (BITTENCOURT et al., 1999). Como resultado verifica-se que a política de criação de PAs, tal como executada, não tem conduzido à sua sustentabilidade, dificultando a consolidação de unidades rurais e impedindo a autonomia das famílias que se mantêm dependentes de auxílios e aposentadorias (GRAZIANO NETO, 1998; KAGEYAMA; BERGAMASCO; OLIVEIRA, 2006). Em certos casos, a situação é tão grave que leva à venda (ilegal) das parcelas ou até mesmo ao abandono dos lotes.

Tendo em vista o quadro deficitário instaurado, alguns estudos como Bittencourt et al. (1999) e Sparovek $(2003 ; 2005)$ têm focado a avaliação da situação atual dos PAs a partir de multicritérios, visando identificar fatores que funcionam como barreiras ao seu desenvolvimento, sobretudo econômico e, a partir disso, subsidiar a elaboração de novos planos e revisão das ações praticadas. Tais estudos têm focado na avaliação de uma série de indicadores de desenvolvimento, mas não têm trabalhado com uma avaliação diretamente atrelada à ideia de sustentabilidade como modelo de viabilização.

Considerando o exposto, o objetivo do presente artigo é apresentar uma proposta metodológica de avaliação da sustentabilidade aplicada aos PAs, que permita identificar o nível de sustentabilidade de um PA ou de um ou mais de seus lotes específicos com dificuldades, a partir de um sistema de pontos simples e objetivo, possibilitando reconhecer os fatores que retardam e os que impulsionam seu desenvolvimento sustentável. A metodologia baseia-se em indicadores de sustentabilidade, ancorados nas Funções do Uso das Terras (FUTs), as quais correspondem a mercadorias e serviços fornecidos pelos diferentes usos da terra que, juntos, sintetizam os mais relevantes aspectos da economia, meio ambiente e comunidade de uma dada área.

A metodologia apresentada faz parte dos resultados de pesquisa desenvolvida em nível de Mestrado e trata-se de uma primeira formulação. A mesma foi testada com sucesso em dois PAs do estado de Goiás, ambiental e socioeconomicamente bastante contrastados, um localizado na região nordeste e outro na porção sudeste e espera-se que possa ser testada em PAs de outras regiões do país subsidiando ações e mesmo políticas voltadas à melhoria do seu desempenho numa perspectiva sustentável.

\section{A SUSTENTABILIDADE COMO MODELO DE DESENVOLVIMENTO EM PAS}

$\begin{array}{lllll}\text { Caminhos de Geografia } & \text { Uberlândia-MG } & \text { v. 23, n. } 85 & \text { fev./2022 } & \text { p. 157-176 Página } 158\end{array}$


Medeiros (2015) destaca que, recentemente, a reforma agrária brasileira vem ganhando novos contornos, indo além das demandas de democratização fundiária. Ferreira (1994), destaca que em decorrência, o conceito de assentamento rural se transformou e se expandiu, no sentido de incluir uma série de medidas necessárias à fixação e transformação dos beneficiários de meros proprietários de terra em verdadeiros produtores rurais autônomos. Essa transição envolve a superação de modelos de desenvolvimento antigos, defasados e pouco eficientes, visando a implementação de modelos mais modernos e plurais, que levem em conta as realidades locais e as demandas dos beneficiários propiciando o fortalecimento das unidades familiares e a utilização racional dos recursos naturais disponíveis.

Anjos (2003) trabalha com a ideia de pluriatividade como forma de atualizar os modelos de desenvolvimento, principalmente para as pequenas explorações. A pluriatividade identifica novos critérios para valorar os espaços rurais e redefinir sua função e o status da agricultura nesse processo. Nesse sentido, o autor destaca "a importância das atividades agrícolas para o equilíbrio territorial e o dinamismo das zonas rurais, assim como para a preservação dos recursos naturais que, simultaneamente, passam a ocupar o primeiro plano na definição de novas políticas agrárias" (Anjos, 2003, p. 16).

A pluriatividade pode ser garantida, por exemplo, através da adoção de modelos de desenvolvimento baseados na ideia multifuncional de sustentabilidade. Sachs (2009) perfilha uma concepção de sustentabilidade como a harmonização entre oito dimensões (social; cultural; ecológico; ambiental; territorial; econômico; político nacional e político internacional), as quais devem ser estimuladas em conjunto. A Organização das Nações Unidas para Alimentação e Agricultura (FAO) defende que o desenvolvimento sustentável no setor da agricultura "... se baseia na conservação de recursos genéticos, terra, água, flora e fauna e é ambientalmente não degradante, tecnicamente adequado, economicamente viável e socialmente aceitável" (FAO, 1989, p. 65). Kinsella et al. (2000) e Kageyama (2004) afirmam que o desenvolvimento sustentável tem se firmado como um modelo agregador, com grande potencial para promover o fortalecimento das unidades rurais familiares, por ter como base a conservação dos recursos naturais aliada à promoção de bem-estar social e o desenvolvimento econômico. O INCRA, por sua vez, incorporou às suas diretrizes o conceito de assentamento rural sustentável numa tentativa de atualizar suas ações.

No entanto, persiste um conflito notável entre o modelo de reforma agrária eficaz e o modelo praticado, dadas as restrições técnicas, orçamentárias e políticas (Ferreira, 1994; Mattei, 2012), os quais promovem entraves ao desenvolvimento sustentável. Tais entraves demandam verificar a situação dos PAs e, com isso, propor melhorias por meio de revisões voltadas à consolidação de sistemas agrícolas sustentáveis.

\section{A AVALIAÇÃO DA SUSTENTABILIDADE EM PAS}

A metodologia proposta por Pérez-Soba et al. (2008), aplicada ao presente trabalho, baseia-se na avaliação das Funções de Uso das Terras (FUTs), a qual visa estabelecer as inter-relações entre as dimensões econômica, social e ambiental mais relevantes em uma dada região ou localidade, em estreita relação com o uso das terras. A adoção dessa proposta metodológica deve-se a: (a) possibilidade de diagnóstico relativamente rápido; (b) interlocução fácil entre as dimensões da sustentabilidade e os respectivos indicadores; (c) flexibilidade e adequação à temática trabalhada; (d) possibilidade dos resultados obtidos subsidiarem a elaboração de planos e projetos mais adequados à realidade.

O modelo original proposto por Pérez-Soba et al. (2008), é composto por sete Funções de Uso da Terra (FUTs) distribuídas pelas três dimensões da sustentabilidade, a Social, a Econômica e a Ambiental (Quadro 1). 
Quadro 1. Articulação entre as dimensões da sustentabilidade e as funções de uso da terra

\begin{tabular}{|c|c|}
\hline Dimensões da sustentabilidade & $\begin{array}{c}\text { Funções de uso da terra (FUT) } \\
\text { Oferta de trabalho } \\
\text { Qualidade de Vida } \\
\text { Cultural }\end{array}$ \\
\hline Econômica & $\begin{array}{c}\text { Produção independente da terra e } \\
\text { residual }\end{array}$ \\
\hline Ambiental & $\begin{array}{c}\text { Produção dependente da terra } \\
\text { Transporte }\end{array}$ \\
\hline & $\begin{array}{c}\text { Provisão de recursos abióticos } \\
\text { Provisão de recursos bióticos } \\
\text { Manutenção de processos } \\
\text { ecossistêmicos }\end{array}$ \\
\hline
\end{tabular}

Fonte: adaptado de Pérez-Soba et al., 2008.

Cada FUT contempla um rol de indicadores de sustentabilidade selecionados conforme o tema e a finalidade do estudo. Indicadores podem ser quantitativos e/ou qualitativos atribuídos às variáveis que se relacionam ao objeto, no caso, aos PAs. Smeets e Weterings (1999) destacam que indicadores sempre simplificam uma realidade complexa por focarem os aspectos relevantes. Malheiros, Philippi Jr e Coutinho (2008) destacam sua importância nas etapas de diagnóstico e de prognóstico, como ferramentas que permitem obter uma visão de conjunto devido uma maior integração das variáveis envolvidas, e na etapa de implementação, por possibilitar verificar a relação com as metas estabelecidas. Turetta e Coutinho (2015) acrescentam que os indicadores transmitem a informação técnica de forma sintética, preservando o significado original dos dados e usando apenas as variáveis que melhor expressam os objetivos. Leite Júnior et al. (2013) também consideram a fácil representação dos resultados e assinalam a necessidade de mudanças no comportamento dos agentes, para auxiliar, inclusive, nos ajustes institucionais e na direção das políticas, ajudando na análise e no planejamento.

\section{PROPOSTA METODOLÓGICA DE AVALIAÇÃO DA SUSTENTABILIDADE EM ASSENTAMENTOS RURAIS}

A proposta metodológica de avaliação da sustentabilidade em assentamentos rurais aqui apresentada é composta por 9 etapas (Figura 1). 
Figura 1. Estrutura da proposta metodológica de avaliação da sustentabilidade em PAs

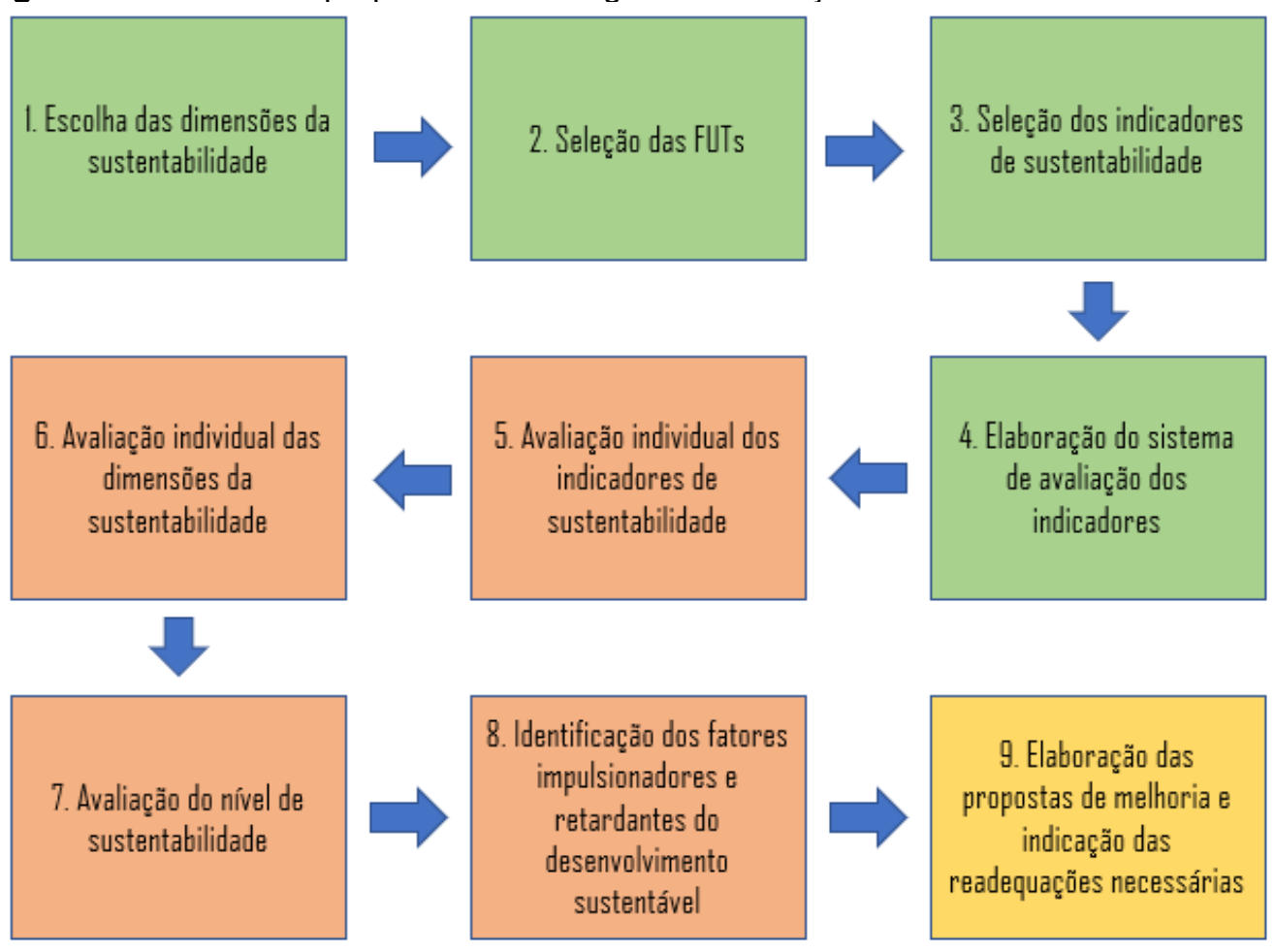

Fonte: Elaboração própria.

As etapas 1 a 4 compõem o grupo Pré-diagnóstico, cujo objetivo é definir os critérios de avaliação da sustentabilidade. As etapas 5 a 8 compõem o grupo Diagnóstico, cuja finalidade é identificar as variáveis que comprometem a sustentabilidade. E a etapa 9 compõe o grupo de Planejamento, no qual variáveis que implicam limitações de desempenho devem ser alvo de ações específicas para reverter o quadro não sustentável. A seguir são descritas as etapas e respetivas avaliações da sustentabilidade de PAs para cada grupo, dimensão e FUT.

\section{Grupo Pré-diagnóstico}

Optou-se por manter as três dimensões da sustentabilidade utilizadas por Pérez-Soba et al. (2008) por sua relevância para os PAs. Na dimensão social as FUTs selecionadas foram: a promoção de qualidade de vida a partir do acesso à serviços básicos, a ocupação do homem do campo em atividades ligadas à exploração produtiva da terra, a geração de renda a partir da exploração de suas terras e a organização coletiva na forma de organizações, sindicatos e associações voltadas à produção e ao estímulo da participação coletiva e engajamento social, auxiliando as articulações pelo provimento de serviços junto à Prefeitura, INCRA e demais órgãos envolvidos na política agrária. $\mathrm{Na}$ dimensão econômica foram arroladas as funções relativas à organização da produção, que envolvem as condições necessárias ao aproveitamento econômico das terras, a sua utilização efetiva e a integração ao contexto socioeconômico, sobretudo local e regional. E na dimensão ambiental foram arroladas as funções relacionadas ao uso das terras, como a necessidade de conservação de recursos bióticos e abióticos disponíveis.

O critério utilizado para a seleção de indicadores seguiu o mesmo princípio de relevância para os PAs, sendo eles qualitativos e quantitativos, além de multifuncionais, para demonstrar de forma simples, clara e objetiva a situação de sustentabilidade atual. Ao todo foram selecionados dezoito indicadores, sendo cinco sociais, oito econômicos e cinco ambientais, todos avaliados numa mesma escala de pontos de 0 a 10, mesmo para os indicadores qualitativos, de modo que o desempenho de todos fosse visualizado nessa mesma escala de pontos. Quanto mais distante de 0 e próximo de 10 for o valor do indicador, melhor seu desempenho, dando-se o inverso quanto mais próximo de 0 . A articulação entre as dimensões da sustentabilidade, as FUTs e os indicadores de sustentabilidade

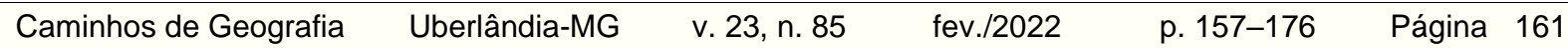


Quadro 2. Sustentabilidade ambiental: articulação entre funções e indicadores SUSTENTABILIDADE AMBIENTAL

\begin{tabular}{|c|c|c|c|c|}
\hline FUT & Indicadores & Situação ideal & Procedimento & $\begin{array}{l}\text { Fonte dos } \\
\text { dados }\end{array}$ \\
\hline 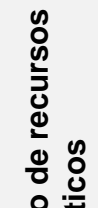 & $\begin{array}{l}\text { 1. Área de } \\
\text { Preservação } \\
\text { Permanente } \\
\text { (APP) } \\
\text { preservada }\end{array}$ & $\begin{array}{lrr}\text { Espera-se que as APPs } & \text { estejam } \\
\text { delimitadas } & \text { conforme } & \text { as } \\
\text { especificações } & \text { da } & \text { legislação } \\
\text { ambiental e que } & \text { estejam } \\
\text { devidamente preservadas. } & \end{array}$ & $\begin{array}{l}\text { Considerou-se a \% } \\
\text { de APP preservada }\end{array}$ & $\begin{array}{l}\text { Informações do } \\
\text { Cadastro } \\
\text { Ambiental Rural } \\
\text { CAR }\end{array}$ \\
\hline 敢 & $\begin{array}{l}\text { 2. Reserva } \\
\text { Legal (RL) } \\
\text { preservada }\end{array}$ & $\begin{array}{lrrr}\text { Espera-se que } & \text { a } R L & \text { esteja } \\
\text { delimitada } & \text { conforme } & \text { as } \\
\text { especificações } & \text { da } & \text { legislação } \\
\text { ambiental e } & \text { que } & \text { estejam } \\
\text { devidamente preservadas. } & \end{array}$ & $\begin{array}{l}\text { Considerou-se a \% } \\
\text { de RL preservada }\end{array}$ & $\begin{array}{c}\text { Informações do } \\
\text { CAR }\end{array}$ \\
\hline \multirow{3}{*}{ 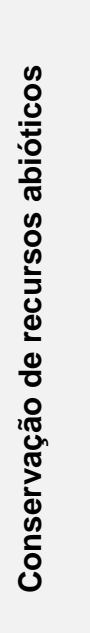 } & $\begin{array}{l}3 . \\
\text { Suscetibilidade } \\
\text { à erosão } \\
\text { laminar }\end{array}$ & $\begin{array}{l}\text { Espera-se que a maior parte das } \\
\text { terras apresentam baixa à moderada } \\
\text { suscetibilidade à erosão laminar. }\end{array}$ & $\begin{array}{l}\text { Considerou-se a \% } \\
\text { de terras que } \\
\text { apresentam baixo } \\
\text { e/ou nulo potencial } \\
\text { para perda de solos } \\
\text { por erosão laminar }\end{array}$ & $\begin{array}{l}\text { Mapa de } \\
\text { Suscetibilidade à } \\
\text { erosão laminar }\end{array}$ \\
\hline & $\begin{array}{l}\text { 4. Potencial de } \\
\text { perda de solo }\end{array}$ & $\begin{array}{l}\text { Espera-se que o uso e o manejo do } \\
\text { solo não estejam sobrecarregando a } \\
\text { capacidade de suporte de modo } \\
\text { aumentar o potencial erosivo. }\end{array}$ & $\begin{array}{l}\text { A avaliação do } \\
\text { indicador levou em } \\
\text { conta somente a \% } \\
\text { terras com baixo } \\
\text { potencial. }\end{array}$ & $\begin{array}{l}\text { Mapa de } \\
\text { Potencial à } \\
\text { erosão laminar }\end{array}$ \\
\hline & $\begin{array}{l}5 . \\
\text { Adequabilidade } \\
\text { de Uso das } \\
\text { terras }\end{array}$ & $\begin{array}{l}\text { Espera-se que o uso do solo esteja } \\
\text { de acordo com a capacidade de uso } \\
\text { das terras, não ficando nem acima e } \\
\text { nem abaixo do potencial. }\end{array}$ & $\begin{array}{c}\% \text { de Terras com } \\
\text { uso adequado }\end{array}$ & $\begin{array}{l}\text { Mapa de } \\
\text { Adequabilidade } \\
\text { de Uso }\end{array}$ \\
\hline
\end{tabular}

Fonte: Elaboração dos autores.

\section{Indicadores Econômicos}

A seleção dos indicadores econômicos considerou as possibilidades de geração de renda baseada na exploração econômica da terra. Nesse sentido, julgou-se relevante: 1) o potencial produtivo das terras como sendo a condição básica necessária para que haja aproveitamento produtivo da terra; 2) considerou-se frente ao potencial, a área efetivamente aproveitada, por cultivos e pastagem, que estejam em concordância com a capacidade de uso das terras; 3 ) as condições técnicas necessárias para que a exploração econômica da terra seja a mais racional possível, crédito rural e assistência técnica, e 4) a possibilidade de geração de diversificação produtiva e de escoamento da produção a partir da análise do contexto socioeconômico de locação do PA. O quadro 3 resume o exposto e mostra como avaliar.

O potencial produtivo das terras é a condição básica para a viabilização da sustentabilidade dos PAs, pois espera-se que as famílias possam explorar suas terras e gerar renda. Nesse sentido, a avaliação das condições físico-químicas dos solos e o levantamento das vantagens e das limitações produtivas é fundamental, pois subsidiam a organização racional do uso das terras, identificando os tipos de uso e de manejo mais adequados e evitando a ocupação de terras frágeis por usos que as sobrecarreguem ou a subutilização de terras com potencial agrícola. O índice desse indicador referese a soma das terras com potencial produtivo para usos convencionais e que apresentam limitações leves e de fácil reversão. Recomenda-se que se utilize o Sistema de Capacidade de Uso das Terras (LEPSCH et al., 2015) pela sua praticidade e pela sua aplicação voltada à conservação dos solos. 
Quadro 3. Sustentabilidade econômica: articulação entre funções e indicadores

\section{SUSTENTABILIDADE ECONÔMICA}

\begin{tabular}{|c|c|c|c|c|}
\hline FUT & Indicadores & Situação ideal & Procedimento & $\begin{array}{l}\text { Fonte dos } \\
\text { dados }\end{array}$ \\
\hline \multirow{7}{*}{ 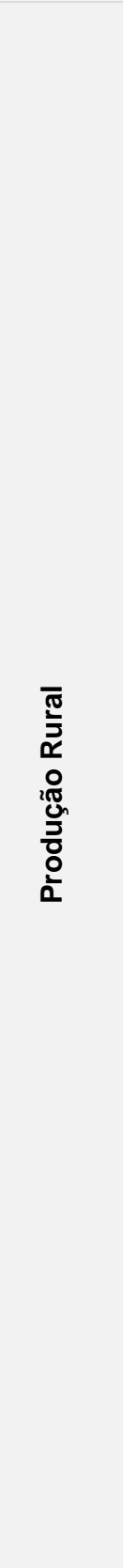 } & $\begin{array}{l}\text { 6. Potencial } \\
\text { produtivo } \\
\text { das terras }\end{array}$ & $\begin{array}{l}\text { As terras favorecem a exploração produtiva na } \\
\text { maioria dos lotes, podendo apresentar restrições } \\
\text { produtivas leves e de fácil reversão. }\end{array}$ & $\begin{array}{l}\text { Soma das terras } \\
\text { com potencial } \\
\text { produtivo para } \\
\text { usos } \\
\text { convencionais e } \\
\text { limitações leves, } \\
\text { de fácil } \\
\text { reversão. }\end{array}$ & $\begin{array}{c}\text { Mapa de } \\
\text { Capacidade } \\
\text { de Uso das } \\
\text { Terras }\end{array}$ \\
\hline & $\begin{array}{l}\text { 7. Área } \\
\text { cultivada } \\
\text { (ha) efetiva }\end{array}$ & $\begin{array}{l}\text { As terras têm capacidade para cultivos diversos, } \\
\text { atendendo a fins de subsistência e à } \\
\text { comercialização e as famílias estão aproveitando } \\
\text { ao máximo o potencial produtivo. }\end{array}$ & $\begin{array}{l}\text { \% Área com } \\
\text { potencial / \% } \\
\text { área } \\
\text { efetivamente } \\
\text { ocupada } \\
\text { (AP/AEO) }\end{array}$ & $\begin{array}{l}\text { Mapa de } \\
\text { uso e } \\
\text { cobertura do } \\
\text { solo }\end{array}$ \\
\hline & $\begin{array}{l}\text { 8. Área de } \\
\text { pasto (ha) } \\
\text { efetiva }\end{array}$ & $\begin{array}{l}\text { Há terra em extensão suficiente para o } \\
\text { estabelecimento de pasto voltada à pecuária } \\
\text { extensiva e que a terra tem potencial de uso } \\
\text { para esse fim. }\end{array}$ & $\begin{array}{l}\text { \% Área com } \\
\text { potencial / \% } \\
\text { área } \\
\text { efetivamente } \\
\text { ocupada } \\
\text { (AP/AEO) }\end{array}$ & $\begin{array}{l}\text { Mapa de } \\
\text { uso e } \\
\text { cobertura do } \\
\text { solo }\end{array}$ \\
\hline & $\begin{array}{l}9 . \\
\text { Diversificaçã } \\
\text { o produtiva }\end{array}$ & $\begin{array}{l}\text { As famílias reduzem a dependência de uma só } \\
\text { exploração, a partir da diversificação produtiva, } \\
\text { evitando, assim, a monocultura e aumentando as } \\
\text { fontes de renda agrícola da terra, impulsionando } \\
\text { a segurança alimentar. }\end{array}$ & $\begin{array}{l}\text { Atividades } \\
\text { econômicas } \\
\text { predominantes } \\
\text { em cada lote. } \\
\text { Ver quadro } 10 \text {. }\end{array}$ & $\begin{array}{l}\text { Mapa de } \\
\text { uso e } \\
\text { cobertura do } \\
\text { solo }\end{array}$ \\
\hline & $\begin{array}{l}\text { 10. Adoção } \\
\text { de práticas } \\
\text { produtivas } \\
\text { sustentáveis }\end{array}$ & $\begin{array}{l}\text { Uso de adubação verde, controle natural de } \\
\text { pragas e de ervas daninhas, rotação de culturas, } \\
\text { plantio direto, uso eficaz de sistemas de irrigação } \\
\text { que evitem o desperdício de água, adoção de } \\
\text { práticas agroecológicas e da agricultura } \\
\text { orgânica, além de planejamento do uso } \\
\text { condicionado às condições produtivas das terras } \\
\text { e o cumprimento da legislação trabalhista. }\end{array}$ & $\begin{array}{l}\text { Soma de Sub- } \\
\text { Indicadores }\end{array}$ & $\begin{array}{l}\text { Aplicação } \\
\text { de } \\
\text { questionário } \\
\text { s e } \\
\text { observação } \\
\text { em campo }\end{array}$ \\
\hline & $\begin{array}{l}\text { 11. Acesso à } \\
\text { linhas } \\
\text { crédito }\end{array}$ & $\begin{array}{l}\text { As famílias têm acesso a linhas de crédito } \\
\text { voltadas à agricultura familiar, suficientes para } \\
\text { atender suas demandas, podendo reverter esse } \\
\text { recurso, em benfeitorias e contam com o devido } \\
\text { amparo técnico. }\end{array}$ & $\begin{array}{l}\text { \% de famílias } \\
\text { que relataram } \\
\text { acessar crédito } \\
\text { rural } \\
\text { recentemente. } \\
\text { Ver quadro } 5 .\end{array}$ & $\begin{array}{l}\text { aplicação de } \\
\text { questionário }\end{array}$ \\
\hline & $\begin{array}{l}12 . \\
\text { Assistência } \\
\text { técnica } \\
\text { continuada }\end{array}$ & $\begin{array}{l}\text { Os órgãos de amparo a assentamentos rurais } \\
\text { oferecem amparo técnico continuado e } \\
\text { compatível com a realidade produtiva das } \\
\text { famílias. }\end{array}$ & $\begin{array}{l}\text { \% de famílias } \\
\text { que relataram } \\
\text { acessar } \\
\text { assistência } \\
\text { técnica } \\
\text { continuada. Ver } \\
\text { quadro } 5 \text {. }\end{array}$ & $\begin{array}{l}\text { aplicação de } \\
\text { questionário }\end{array}$ \\
\hline 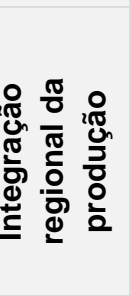 & $\begin{array}{l}\text { 13. Contexto } \\
\text { socioeconô } \\
\text { mico }\end{array}$ & $\begin{array}{l}\text { A produção está articulada com seu contexto } \\
\text { produtivo, integrada à cadeia produtiva } \\
\text { local/regional e à canais de comercialização da } \\
\text { produção. Há infraestrutura básica para } \\
\text { escoamento da produção e proximidade com } \\
\text { centros consumidores e de serviços num raio de } \\
30 \mathrm{~km} \text {, a fim de reduzir os custos com transporte } \\
\text { e poluição do ar. }\end{array}$ & Ver quadro 6 & $\begin{array}{l}\text { Mapa de } \\
\text { localização } \\
\text { do PA e da } \\
\text { sede dos } \\
\text { municípios } \\
\text { próximos e } \\
\text { aplicação de } \\
\text { questionário }\end{array}$ \\
\hline
\end{tabular}

Fonte: Elaboração dos autores. 
É importante que o solo seja, de fato, aproveitado e bem pelos próprios beneficiários. Seu aproveitamento efetivo indica que a terra está cumprindo uma função produtiva, fato importante para fins de subsistência, segurança alimentar e renda, de modo a reduzir as chances de subutilização do potencial produtivo das terras, de abandono das parcelas e de venda (ilegal) dos lotes. As atividades rurais convencionais como agricultura e pastagem são indicadoras do uso efetivo das terras. A avaliação desses indicadores considerou a utilização racional do solo e, portanto, apenas o uso efetivo situado em terras com potencial para suportá-lo, excluindo-se o uso efetivo em terras que não suportam tais atividades.

Ainda acerca do uso efetivo do solo, a literatura tem mostrado que quanto mais diversa for a utilização, maior é a possibilidade de aumento de renda, de intensificação do trabalho coletivo, organização sociopolítica e produtiva, bem como instrumento de construção de circuitos de comercialização, de agregação de valor e até mesmo de promoção de segurança alimentar (RATHMANN et al.,2008; RIBEIRO, 2015). Nesse sentido, o indicador diversificação produtiva é representativo da dinâmica produtiva dos PAs e pode ser avaliado considerando as atividades predominantes em cada lote e a sua participação na composição final da renda. O nível de diversificação pode ser aferido a partir da classificação apresentada no quadro 4.

\section{Quadro 4. Nível de diversificação produtiva}

PONTOS NÍVEL DE DIVERSIFICAÇÃO PRODUTIVA

10 construção de circuitos comerciais incipiente.
Alta. Não há dependência econômica de um só item pois a produção é diversificada. A diversificação produtiva garante a segurança alimentar e impulsiona 0 trabalho coletivo, além de favorecer a construção de múltiplos circuitos de comercialização.

Média. A renda é composta por dois ou mais itens, reduzindo moderadamente a dependência econômica de apenas um item. A diversificação produtiva, apesar de moderada, leva a um aumento na intensidade ou na demanda por trabalho coletivo e começa a favorecer a construção de circuitos múltiplos de comercialização.

Baixa. A renda é composta por dois itens, o que reduz levemente a dependência econômica. No entanto, ainda expressa baixa intensidade do trabalho coletivo e

Ausente. A renda depende totalmente de apenas um item, levando a total vulnerabilidade econômica do produtor. Essa dependência impacta negativamente a renda e a segurança alimentar, reduz a intensidade do trabalho coletivo e acaba com a chance de construção de múltiplos circuitos de comercialização.

Fonte: Elaboração dos autores.

Assim como se espera que o uso efetivo do solo esteja de acordo com o potencial produtivo das terras, se espera também que sejam adotadas práticas produtivas condizentes com o modelo sustentável de desenvolvimento. Nesse sentido alguns subindicadores podem ser avaliados para reforçar essa questão, entre eles: 1) a valorização da agricultura familiar, 2) a adoção de adubação verde, 3) o controle natural de pragas e ervas daninhas, 4) a rotação de culturas, 5) a implementação de sistemas de irrigação eficazes visando o não desperdício de água, 6) o cumprimento da legislação trabalhista e ambiental, 7) o desenho produtivo a partir da adoção de modelos agroecológicos ou da agricultura orgânica, 8) o planejamento de uso e manejo, 9) o não desmate de florestas e matas para a ampliação da área de produção, 10) o uso de agroenergia. A avaliação envolve o cumprimento ou não do subindicador, de modo que seja atribuído um (1) ponto para o cumprimento e quando da observação da não adoção da prática ou descumprimento dela, não há atribuição de ponto.

Crédito rural e assistência técnica são importantes por serem condições básicas para a exploração da terra visando a maximização dos resultados produtivos. Ferreira (1994, p. 43), ressalta que "se por um lado, a noção de assentamento envolve a fixação do homem à terra, não se pode desvincular do provimento de condições para torná-la produtiva". Da mesma maneira, o bom desempenho desses dois indicadores estabelece relação com o acesso a políticas públicas recentes voltadas para a agricultura familiar e associa-se também com a qualidade dos serviços prestados aos PAs, os quais são previstos nas fases de consolidação e estruturação. Para os indicadores Crédito rural e Assistência técnica, utilizou-se os dados obtidos por meio da análise da aplicação de questionário junto às famílias. A avaliação da situação dos PAs quanto a esses dois indicadores pode ser realizada a partir da classificação exposta no quadro 5.

$\begin{array}{llllll}\text { Caminhos de Geografia } & \text { Uberlândia-MG } & \text { v. 23, n. } 85 & \text { fev./2022 } & \text { p. 157-176 } & \text { Página } 165\end{array}$




\section{PONTOS}

Quadro 5. Classificação dos indicadores Crédito rural e Assistência técnica.

\section{CREDITO RURAL}

10

5

0

PONTOS

10

6,6

As famílias conseguem acessar crédito produtivo com facilidade via INCRA ou por conta própria. $\mathrm{O}$ crédito oferecido atende as necessidades produtivas e é empregado com o amparo técnico necessário. A satisfação quanto às opções de pagamento são predominante e não provocam o endividamento das famílias ou comprometimento de grande parte da renda por um longo período.

As famílias conseguem acessar crédito mesmo que com dificuldade via INCRA ou por conta própria, mas após o recebimento existe algum problema referente a melhor aplicação desse recurso e com o pagamento das parcelas, gerando algum tipo de insatisfação.

As famílias não acessam linhas de crédito de qualquer natureza por conta de algum fator. Esse fato, leva a estagnação produtiva e extrema insatisfação. Podem também ocorrer a situação na qual as famílias acessam crédito com dificuldade via INCRA ou por conta própria, mas não investem o recurso com o devido amparo técnico, não rendendo nenhum tipo de retorno produtivo, levando a insatisfação e ao endividamento das famílias.

\section{ASSISTENCIA TÉCNICA}

As famílias recebem regularmente assistência técnica, ou apresentam condições de contratarem a assistência de que precisam por conta própria. É compatível com a realidade produtiva do assentamento e é baseada em noções de sustentabilidade. A satisfação com a assistência recebida é predominante, impulsionando os resultados produtivos.

As famílias recebem assistência técnica de forma regular. Ela é adequada a realidade produtiva dos assentamentos, mas os seus resultados produtivos respondem em parte à expectativa das famílias, podendo ser aprimorada.

As famílias recebem assistência técnica, mas não é regular. Ela não é adequada a realidade produtiva e os resultados práticos são incipientes, mostrando pouquíssimas melhorias nas condições produtivas das famílias.

As famílias não recebem nenhum tipo de assistência técnica, nem apresentam condições de contratarem por conta própria. A ausência de assistência leva a uma estagnação produtiva ou ao uso inadequado do solo.

Fonte: Elaboração dos autores.

Bittencourt et al. (1999) haviam trabalhado com a importância de se avaliar o contexto socioeconômico dos PAs por identificar que os mais desenvolvidos eram os que preservavam maior proximidade com sedes de município e mercados locais, enquanto os menos desenvolvidos seriam os afastados das aglomerações urbanas, onde o acesso a esses centros é oneroso e difícil em razão das condições precárias de estradas e custos gerais do deslocamento. O que se espera é que a organização produtiva dos PAs sempre leve em conta o seu contexto socioeconômico e busque formas de se integrar às cadeias produtivas regionais e locais, evitando o isolamento. O quadro 6 mostra o sistema classificação do indicador contexto socioeconômico.

\section{PONTOS}

Quadro 6. Classificação do indicador Integração ao contexto socioeconômico regional

\section{CONTEXTO SÓCIOECONÔMICO}

A produção se articula com o seu contexto se integrando à cadeia de produção local/regional e à canais de comercialização da produção. Há proximidade com centros de aglomeração de pessoas e serviços dentro de um raio de $30 \mathrm{~km}$, e existe infraestrutura básica para que o acesso a eles ocorra possibilitando o escoamento da produção.

Há centros de aglomeração de pessoas e serviços nas proximidades do PA e com

6,6 isso, possíveis canais de comercialização da produção. No entanto, os assentamentos se integram com dificuldade a esses canais. isso, possíveis canais de comercialização da produção. No entanto, ele não se integra 
a esses canais.

Não há centros de aglomeração de pessoas e serviços dentro de um raio de $30 \mathrm{~km}$ que possibilitem viabilidade da comercialização da produção do PA. A ausência de integração produtiva leva a uma situação de isolamento.

Fonte: Elaboração dos autores

\section{Indicadores Sociais}

O levantamento bibliográfico mostrou que indicadores sociais mais relevantes para os PAs se referem à geração de emprego e renda, à organização coletiva das famílias e ao acesso a serviços básicos como educação, saúde, saneamento, água potável, energia elétrica, coleta de lixo e infraestrutura de laser e cultura. Assim, considerando esses aspectos sociais para se pensar a sustentabilidade social em PAs, selecionou-se cinco indicadores: emprego/ocupação, renda, organização coletiva das famílias, acesso à serviços básicos e abastecimento adequado de água (Quadro 7).

Quadro 7. Sustentabilidade social: articulação entre funções e indicadores

\begin{tabular}{|c|c|c|c|c|}
\hline \multicolumn{5}{|c|}{ SUSTENTABILIDADE SOCIAL } \\
\hline FUT & Indicadores & Situação ideal & Como avaliar & Fonte dados \\
\hline \multirow{2}{*}{ 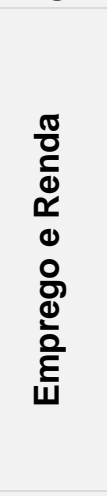 } & $\begin{array}{l}\text { 14. Emprego/ } \\
\text { Ocupação }\end{array}$ & $\begin{array}{l}\text { Os membros adultos das } \\
\text { famílias estão } \\
\text { preferência } \\
\text { produtivamente a sua parcela. }\end{array}$ & $\begin{array}{c}\text { \% das famílias que } \\
\text { declararam que os } \\
\text { seus membros estão } \\
\text { ocupados dentro da } \\
\text { parcela. }\end{array}$ & $\begin{array}{l}\text { aplicação de } \\
\text { questionários }\end{array}$ \\
\hline & 15. Renda & $\begin{array}{l}\text { A renda proveniente da terra é } \\
\text { suficiente para suprir as } \\
\text { necessidades das famílias, e } \\
\text { reduzindo a dependência de } \\
\text { atividades externas que podem } \\
\text { levar, em último caso, ao } \\
\text { abando da parcela. }\end{array}$ & $\begin{array}{l}\text { \% de famílias que } \\
\text { declararam que a } \\
\text { maior parte da renda } \\
\text { advém das atividades } \\
\text { econômicas } \\
\text { desenvolvidas dentro } \\
\text { de sua parcela. }\end{array}$ & $\begin{array}{l}\text { aplicação de } \\
\text { questionários }\end{array}$ \\
\hline \multirow{2}{*}{ 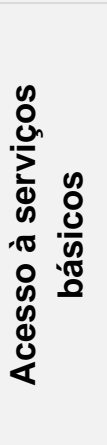 } & $\begin{array}{l}16 . \\
\text { Abasteciment } \\
\text { o adequado } \\
\text { de água }\end{array}$ & $\begin{array}{l}\text { A disponibilidade de água na } \\
\text { parcela, tanto para consumo } \\
\text { próprio das famílias, quanto } \\
\text { para atender as demandas } \\
\text { produtivas é em quantidade } \\
\text { suficiente e e } \\
\text { adequada. qualidade }\end{array}$ & $\begin{array}{l}\text { Considerou-se a \% de } \\
\text { famílias que relataram } \\
\text { acessar água em } \\
\text { níveis e qualidade } \\
\text { suficiente } \mathrm{p} / \mathrm{o} \\
\text { consumo próprio e à } \\
\text { produção. }\end{array}$ & $\begin{array}{l}\text { aplicação de } \\
\text { questionários }\end{array}$ \\
\hline & $\begin{array}{l}\text { 17. Acesso a } \\
\text { serviços } \\
\text { básicos }\end{array}$ & $\begin{array}{l}\text { As famílias acessam serviços } \\
\text { básicos oferecidos pelo } \\
\text { município, satisfazendo as suas } \\
\text { necessidades. }\end{array}$ & $\begin{array}{c}\text { Considerou-se a o } \\
\text { nível de } \\
\text { satisfação/insatisfação. }\end{array}$ & $\begin{array}{l}\text { aplicação de } \\
\text { questionários }\end{array}$ \\
\hline 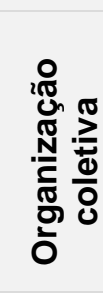 & $\begin{array}{l}18 . \\
\text { Cooperativism } \\
\text { o e } \\
\text { Associativism } \\
\text { o rural }\end{array}$ & $\begin{array}{l}\text { As famílias estão organizadas } \\
\text { em associações e cooperativas } \\
\text { de qualquer natureza, para } \\
\text { fortalecer o potencial produtivo } \\
\text { do PA e se beneficiando das } \\
\text { contribuições decorrentes dessa } \\
\text { prática. }\end{array}$ & $\begin{array}{l}\text { \% das famílias que } \\
\text { declararam participar } \\
\text { da associação do } \\
\text { assentamento. }\end{array}$ & $\begin{array}{l}\text { aplicação de } \\
\text { questionários }\end{array}$ \\
\hline
\end{tabular}

Fonte: Elaboração dos autores.

A avaliação da geração de ocupação/emprego e de renda são essenciais, pois mantêm relação com todos os indicadores econômicos apresentados anteriormente. $\mathrm{O}$ bom desempenho de ambos mostra que foram positivos os resultados de uma série de intervenções na organização produtiva e consolidação dos assentamentos rurais, de modo a gerar ocupação dos indivíduos em atividades econômicas dentro dos seus lotes e promover a integração econômica com o contexto de locação dos assentamentos. Assim, essas funções sociais estão sendo bem cumpridas, reduzindo as chances de abandono das parcelas e aumentando as de promoção de autonomia às famílias. Para a avaliação

$\begin{array}{lllll}\text { Caminhos de Geografia } & \text { Uberlândia-MG } & \text { v. 23, n. } 85 & \text { fev./2022 } & \text { p. 157-176 Página } 167\end{array}$


desses indicadores levou-se em conta as informações obtidas a partir da aplicação de questionários junto às famílias. Para emprego/ocupação, levou-se em conta a \% das famílias que declararam que seus membros estão ocupados em atividades econômicas dentro da sua parcela e para a avaliação do indicador renda, levou-se em conta a \% de famílias que declararam que a maior parte da renda advém das atividades econômicas desenvolvidas dentro de sua parcela. Os índices para os referidos indicadores foram aferidos a partir da classificação apresentada no quadro 8.

\section{PONTOS}

\section{Quadro 8. Classificação dos indicadores Emprego/Ocupação e Renda}

$$
\text { EMPREGO/OCUPAÇÃO }
$$

Os integrantes adultos das famílias estão ocupados dentro da parcela em atividades relativas à sua exploração econômica. A renda mensal é composta em sua totalidade

10 por atividades internas, acabando por completo com a necessidade de complementação de renda por atividades externas ou atividades não relacionadas à produção. O risco de abandono da parcela por questões financeiras é inexistente, pois não existe insegurança financeira.

Os integrantes adultos das famílias se ocupam na maior parte do tempo de atividades produtivas desempenhadas dentro do lote. Uma pequena parte do tempo de trabalho

6,6 mensal é ocupado por atividades externas e/ou não produtivas. A sensação é de que a situação poderia ser melhor, porém atualmente atende suficientemente as necessidades básicas das famílias, não gerando insegurança financeira, ou gerando insegurança financeira leve.

Nem todos os integrantes adultos estão ocupados por atividades desempenhadas

3,3 dentro do assentamento sendo necessário recorrer na maior parte do tempo às atividades externas. A insatisfação e a insegurança são leves, porém não há risco de abandono da parcela.

Nenhum dos membros adultos da parcela encontram-se devidamente ocupados internamente explorando economicamente a sua parcela. A renda mensal é

0 totalmente dependente auxílios e/ou aposentadorias ou dependente de atividades externas a parcela. Essas atividades são esporádicas e inconstantes. A renda decorrente não atende às necessidades básicas das famílias, gerando insegurança e insatisfação financeira, aumentando as chances de abandono da parcela.

\section{PONTOS}

A renda mensal é composta em sua totalidade por atividades internas, acabando por completo com a necessidade de complementação de renda por atividades externas não relacionadas à exploração da própria parcela. $O$ risco de abandono da parcela por questões financeiras é inexistente. A renda supre suficientemente as necessidades básicas das famílias. Não existe insegurança financeira.

A renda em sua maior parte advém de atividades produtivas realizadas dentro do lote. Uma pequena parte é composta por atividades externas e não ligadas à exploração

6,6 da própria parcela. A sensação é de que a situação poderia ser melhor, porém atualmente, atende suficientemente as necessidades básicas das famílias, não gerando insegurança financeira, ou gerando insegurança financeira leve.

A renda não é totalmente assegurada por atividades produtivas realizadas dentro da parcela, sendo em sua maior parte composta por atividades externas e não

3,3 decorrentes da produção. A insatisfação e a insegurança são perceptíveis e por isso, existe risco médio de abandono das parcelas.

A renda mensal é advém totalmente de auxílios e/ou aposentadorias e de atividades externas à parcela. Essas atividades são esporádicas e inconstantes. A renda não atende as necessidades básicas das famílias, geram insegurança e insatisfação financeira, aumentando as chances de abandono das parcelas.

Fonte: Elaboração dos autores.

Quanto à organização coletiva, Guanzirolli (1994) destaca a sua importância, mas também destaca as vantagens de modelos individuais e seu bom desempenho em termos de ganhos de renda e produtividade. $\mathrm{O}$ autor prefere falar em modelos flexíveis que conjugam as vantagens de práticas coletivas e individuais, sem que haja a imposição de um modelo sobre o outro. As vantagens decorrentes de práticas coletivas seriam a possibilidade de internalizar economias de escala (áreas contínuas), a comercialização em escala e a ideia de evitar a diferenciação social dentro do PA. Já as

$\begin{array}{lllll}\text { Caminhos de Geografia } & \text { Uberlândia-MG } & \text { v. 23, n. } 85 & \text { fev./2022 } & \text { p. 157-176 Página } 168\end{array}$


vantagens decorrentes de práticas individuais ou familiares seriam o maior controle individual da terra.

Considerando essas questões, a situação esperada com relação à organização coletiva das famílias é que haja níveis de cooperação entre as famílias de modo a fortalecer o potencial produtivo do PA se beneficiando das contribuições decorrentes de práticas dessa natureza. Para a avaliação desse indicador levou-se em conta a \% das famílias que declararam participar da associação ou cooperativa do assentamento durante a aplicação de questionários junto às famílias. $O$ índice para o referido indicador foi aferido a partir da classificação apresentada no quadro 9.

Quadro 9. Classificação do indicador Organização interna

\begin{tabular}{c|l} 
PONTOS & \multicolumn{1}{c}{ ORGANIZAÇÃO INTERNA } \\
10 & $\begin{array}{l}\text { O assentamento possui associação regulamentada. O associativismo tem ampla } \\
\text { adesão das famílias, e participação ativa. Práticas nesse sentido têm levado ao } \\
\text { fortalecimento das forças produtivas e são vistas com bons olhos pelas famílias do } \\
\text { assentamento. }\end{array}$ \\
7,5 & $\begin{array}{l}\text { O assentamento possui associação regulamentada, mas apresenta adesão } \\
\text { moderada. As famílias são predominantes otimistas quanto a sua contribuição e ela } \\
\text { vem apresentando resultados satisfatórios. }\end{array}$ \\
5 & $\begin{array}{l}\text { O assentamento possui associação regulamentada, apresenta adesão moderada. As } \\
\text { famílias são predominantes otimistas quanto a sua contribuição e vem apresentando } \\
\text { resultados moderados que ainda podem ser melhorados. }\end{array}$ \\
2,5 & $\begin{array}{l}\text { O assentamento possui associação regulamentada, mas possui baixa adesão entre } \\
\text { as famílias. Existe problemas quanto à representação. Os seus resultados em termos } \\
\text { de fortalecimento das forças produtivas são nulos ou incipientes. } \\
\text { Não existe nenhum tipo de associativismo levando a uma total desorganização } \\
\text { produtiva das famílias e/ou a uma individualização produtiva exacerbada. A maior } \\
\text { parte das famílias não enxergam iniciativas nesse sentido com bons olhos. }\end{array}$ \\
0 & \multicolumn{1}{c}{ Fonte: Elaboração dos autores. }
\end{tabular}

Para a avaliação do indicador Acesso à serviços básicos, utilizou-se cinco subindicadores: saúde, educação, energia elétrica e coleta de lixo e acesso à lazer e cultura. Para cada um deles verificou-se o nível de satisfação das famílias atribuindo uma nota para cada sensação. Para satisfação, atribui-se nota 2, para insatisfação nota 1 e para a ausência de serviço não se atribui nenhuma nota. $O$ resultado da soma de cada um dos indicadores vai de 0 a 10, sendo que quanto mais próximo de 10 , maior é a satisfação com os serviços básicos recebidos. O Quadro 10 apresenta a classificação geral do nível de satisfação.

Quadro 10. Classificação do nível de satisfação/insatisfação com os serviços básicos

NÍVEL DE SATISFAÇÃO

$$
\begin{gathered}
7,5-10 \\
5-7,5 \\
2,5-5 \\
0,1-2,5
\end{gathered}
$$$$
0
$$

\section{SENSAÇÃO}

Alta satisfação

Satisfação moderada

Insatisfação moderada

Alta insatisfação

Ausência de oferta de serviços básicos

Fonte: Elaboração dos autores.

Para a avaliação do indicador Acesso à água, levou-se em conta a porcentagem de famílias que declararam que o acesso é regular e suficiente para atender as demandas de consumo e produção. O índice para o referido indicador foi aferido a partir da classificação apresentada no quadro 11.

\section{Quadro 11. Classificação do indicador "Acesso à água"}

\section{PONTOS}

10

\section{ACESSO À ÁGUA}

A fonte de água garante abastecimento ininterrupto e sem a necessidade de racionamento na maior parte do tempo. O volume disponível atende satisfatoriamente em termos de quantidade e qualidade às demandas de consumo e de produção.

$\begin{array}{lllllll}\text { Caminhos de Geografia } & \text { Uberlândia-MG } & \text { v. 23, n. 85 } & \text { fev./2022 } & \text { p. 157-176 } & \text { Página } 169\end{array}$ 

pontuais quanto ao abastecimento e ao atendimento das demandas de consumo próprio e de produção.

O acesso à água é impedido e/ou dificultado por algum fator, comprometendo o abastecimento regular tanto para o consumo próprio quanto para o atendimento da demanda produtiva.

$0 \quad$ Não há acesso a água.

Fonte: Elaboração dos autores.

\section{Avaliação individual das dimensões da sustentabilidade}

Após a obtenção dos valores para cada um dos indicadores, procedeu-se à avaliação individual das dimensões de sustentabilidade. Para cada uma delas foi criado um sistema de classificação simples e objetivo baseado na soma dos valores obtidos por cada um dos indicadores. O valor resultante expressa a condição atual de sua respectiva função de uso da terra, podendo ela estar sendo desempenhada plenamente, assegurando a sustentabilidade ou sendo desempenhada deficitariamente, comprometendo a sua sustentabilidade.

Para a sustentabilidade ambiental, cinco indicadores são avaliados, os quais somados podem atingir a pontuação máxima de 50 pontos. A pontuação mínima é 0 (zero) configurando situação na qual a sustentabilidade encontra-se totalmente comprometida, sendo expressa pela cor vermelha. A pontuação máxima é de 50 (cinquenta) pontos, configurando situação de sustentabilidade ambiental totalmente assegurada. Os valores obtidos são classificados em quatro classes que expressam maior ou menor possibilidade de desenvolvimento sustentável conforme mostra a Figura 3.

Figura 3. Classificação da Sustentabilidade Ambiental

\begin{tabular}{|c|c|}
\hline $\begin{array}{c}\text { SUSTENTABILIDADE } \\
\text { AMBIENTAL }\end{array}$ & Pontos \\
\hline $\begin{array}{l}\text { Sustentabilidade totalmente comprometida. Todos os indicadores são baixos, podendo um deles } \\
\text { apresentar valores médios. Requer readequações de uso imediatas, pois o potencial de perda de solo } \\
\text { é elevado em função de usos intensivos em áreas suscetíveis à erosão. As áreas de interesse ambiental } \\
\text { podem estar delimitadas incorretamente e estão com usos indevidos, os quais comprometem o } \\
\text { desempenho de suas funções ambientais. }\end{array}$ & $0-10$ \\
\hline $\begin{array}{l}\text { Sustentabilidade moderadamente comprometida. Três ou mais indicadores apresentam valores } \\
\text { baixos. As inadequações de uso são médias, mas pedem readequações de imediato visando evitar } \\
\text { chegar aos patamares da classe anterior. A \% de terras com Médio e Alto potencial supera as \% de } \\
\text { terras com baixo potencial erosivo. Terras superutilizadas ocorrem em valores superiores a } 15 \% \text {. }\end{array}$ & $10-20$ \\
\hline $\begin{array}{l}\text { Sustentabilidade moderadamente assegurada. Dois indicadores apresentam valores médios, } \\
\text { podendo um deles ser baixos. Os valores terras superutilizadas são baixos, mas os de subutilização } \\
\text { podem ser elevados. As áreas de interesse ambiental estão delimitadas corretamente, mas podem } \\
\text { ocorrer usos inadequados pontuais dentro delas. Caso existam, elas são leves. A \% de terras que } \\
\text { apresentam potencial erosivo médio é mais elevada do que as que apresentam baixo potencial. }\end{array}$ & $20-30$ \\
\hline $\begin{array}{l}\text { Sustentabilidade Ambiental altamente assegurada. Dois ou três indicadores podem apresentar } \\
\text { valores médios. No entanto, não comprometem áreas extensas. Os valores terras superutilizadas são } \\
\text { baixos, mas os de subutilização podem ser elevados. As áreas de interesse ambiental estão } \\
\text { delimitadas corretamente, mas podem ocorrer usos inadequados pontuais dentro delas. Caso existam, } \\
\text { elas são leves. A \% de terras que apresentam baixo potencial erosivo é mais elevada do que as terras } \\
\text { que apresentam Médio e Alto potencial. }\end{array}$ & $30-40$ \\
\hline $\begin{array}{l}\text { Sustentabilidade ambiental totalmente assegurada. Três ou mais indicadores apresentam valores } \\
\text { elevados, podendo um deles apresentar valores médios. Terras superutilizadas são praticamente } \\
\text { inexistentes. O uso adequado supera a subutilização de terras. As áreas de interesse ambiental estão }\end{array}$ & $40-50$ \\
\hline
\end{tabular}

Fonte: Elaboração dos autores.

Para a sustentabilidade econômica, 8 (oito) indicadores foram avaliados, que somados podem atingir a pontuação máxima de 80 pontos. A pontuação mínima 0 (zero) configura situação de sustentabilidade totalmente comprometida, e a pontuação máxima 80 (oitenta) configura sustentabilidade econômica totalmente assegurada, expressa pela cor verde. Os valores obtidos são 
classificados em cinco classes que expressam maior ou menor possibilidade de desenvolvimento sustentável, como mostra a Figura 4.

Figura 4. Classificação da sustentabilidade econômica

\section{SUSTENTABILIDADE} ECONÔMICA

Sustentabilidade totalmente comprometida. Todos os indicadores são baixos. As terras predominantemente não desempenham adequadamente nenhuma função econômica por conta de limitações técnicas e ambientais. As terras apresentam restrições que inviabilizam qualquer tipo de aproveitamento produtivo convencional (pecuária e agricultura). Outras funções de uso da terra são diretamente afetadas. Não há integração socioeconômica ao seu contexto.

Sustentabilidade moderadamente comprometida. Pelo menos quatro indicadores apresentam valores baixos. As terras apresentam potencial produtivo aproveitado efetivamente em patamares baixos ou médios. As limitações morfopedológicas contribuem com essa limitação em níveis médios. $\mathrm{O}$ acesso à crédito rural e à assistência técnica é ausente ou insuficiente. Baixa integração ao contexto.

Sustentabilidade moderadamente assegurada. Três ou dois indicadores apresentam valores baixos. As terras em sua maioria podem até apresentar bom potencial para o aproveitamento econômico, o qual não é aproveitado efetivamente, fazendo com que a subutilização predomine ou apresente valores muito próximos das terras com uso adequado. As terras desempenham função econômica, mas esta poderia ser melhorada caso o uso se aproximasse da capacidade, observadas as configurações econômicas e os circuitos de comercializações locais e regionais. A diversificação produtiva é baixa ou média e existe algum tipo de problema relacionado à acesso a assistência técnica e/ou crédito.

Sustentabilidade altamente assegurada. As terras apresentam bom à ótimo potencial produtivo, o qual é aproveitado com mais intensidade do que na classe anterior. Um indicador pode apresentar valores baixos, mas ele não chega a comprometer os demais a ponto de se tornar uma restrição ao desempenho da função econômica da terra.

Sustentabilidade totalmente assegurada. As terras desempenhem plenamente a sua função econômica pois todos os indicadores avaliados apresentam valores elevados. Nesse caso, cada indicador é um fator condicionante de sucesso produtivo. O assentamento está completamente integrado ao seu contexto socioeconômico.

Fonte: Elaboração dos autores.

Para a sustentabilidade social, cinco indicadores foram avaliados, os quais somados podem atingir a pontuação máxima de 50 (cinquenta) pontos. A pontuação mínima 0 (zero) configura situação de sustentabilidade totalmente comprometida, expressa pela cor vermelha. A pontuação máxima 50 (cinquenta) configura sustentabilidade social totalmente assegurada, expressa pela cor verde. Os valores obtidos são distribuídos em 5 classes que indicam maior ou menor possibilidade de desenvolvimento sustentável conforme mostra a Figura 5. 
Figura 5. Classificação da Sustentabilidade Social

\begin{tabular}{|c|c|c|}
\hline & & Pontos \\
\hline \multirow{5}{*}{\multicolumn{2}{|c|}{ 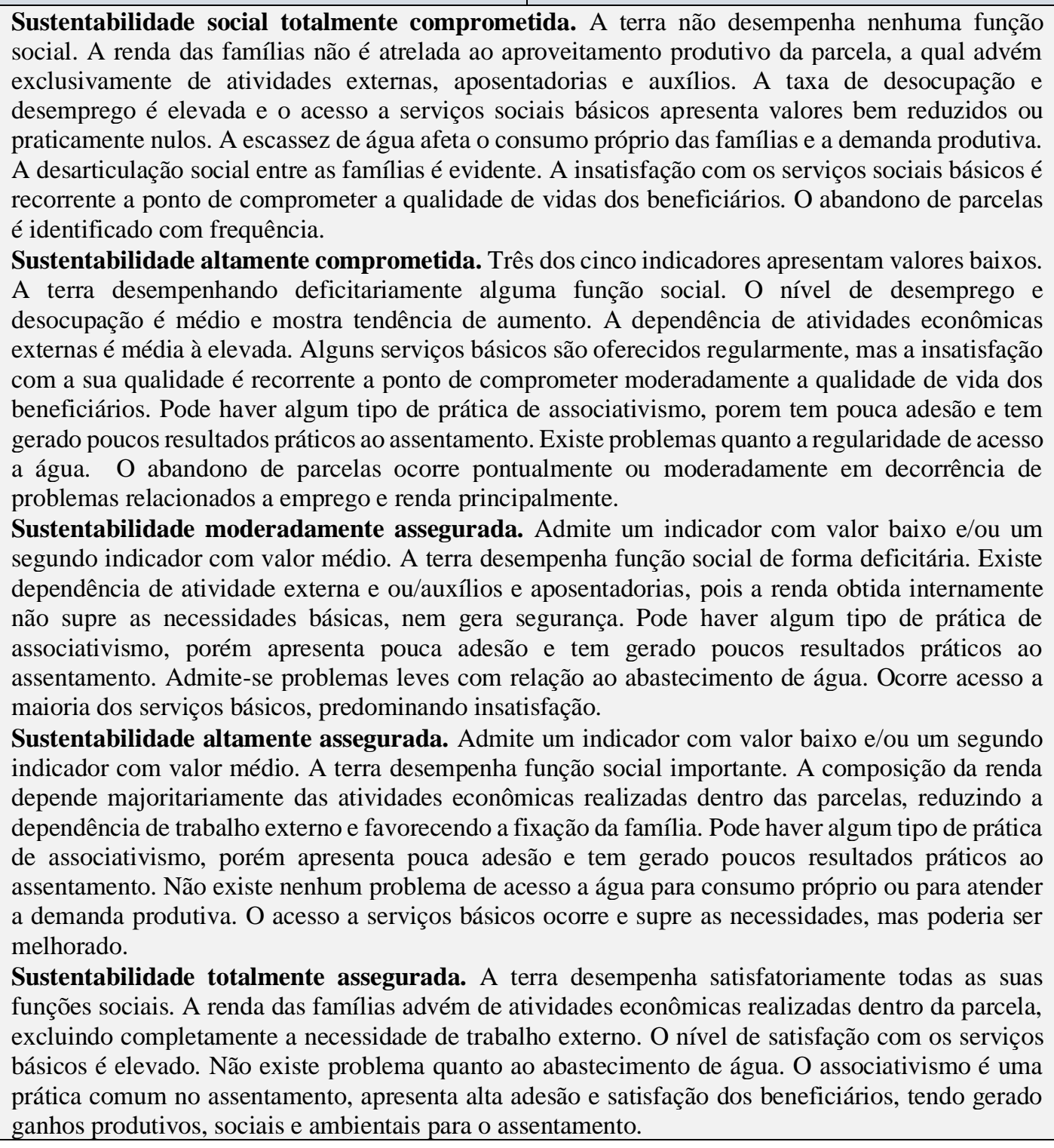 }} & \\
\hline & & $10-20$ \\
\hline & & \\
\hline & & \\
\hline & & \\
\hline
\end{tabular}

Fonte: Elaboração dos autores.

\section{Identificação do Nível de Sustentabilidade}

A identificação do nível de sustentabilidade, última etapa da avaliação do desenvolvimento sustentável, é feita a partir da soma da pontuação das três dimensões avaliadas individualmente. A

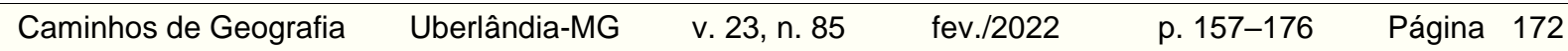


escala de pontuação vai de 0 (zero) a 180 (cento e oitenta), levando em conta os 18 (dezoito) indicadores avaliados. $\mathrm{O}$ valor 0 indica sistema não sustentável, no qual nenhuma das FUTs está sendo desempenhada de modo adequado, expressa pela cor vermelha. O valor 180 mostra desenvolvimento sustentável pleno, em que as FUTs estão sendo perfeitamente desempenhadas, expresso pela cor verde. Os valores são agrupados em cinco classes (Figura 6), observadas a praticidade e objetividade do sistema de classificação. Após a identificação do nível de sustentabilidade do assentamento, é possível identificar os indicadores que o impulsionam e que o retardam, além de verificar o seu peso.

Figura 6. Nível de sustentabilidade

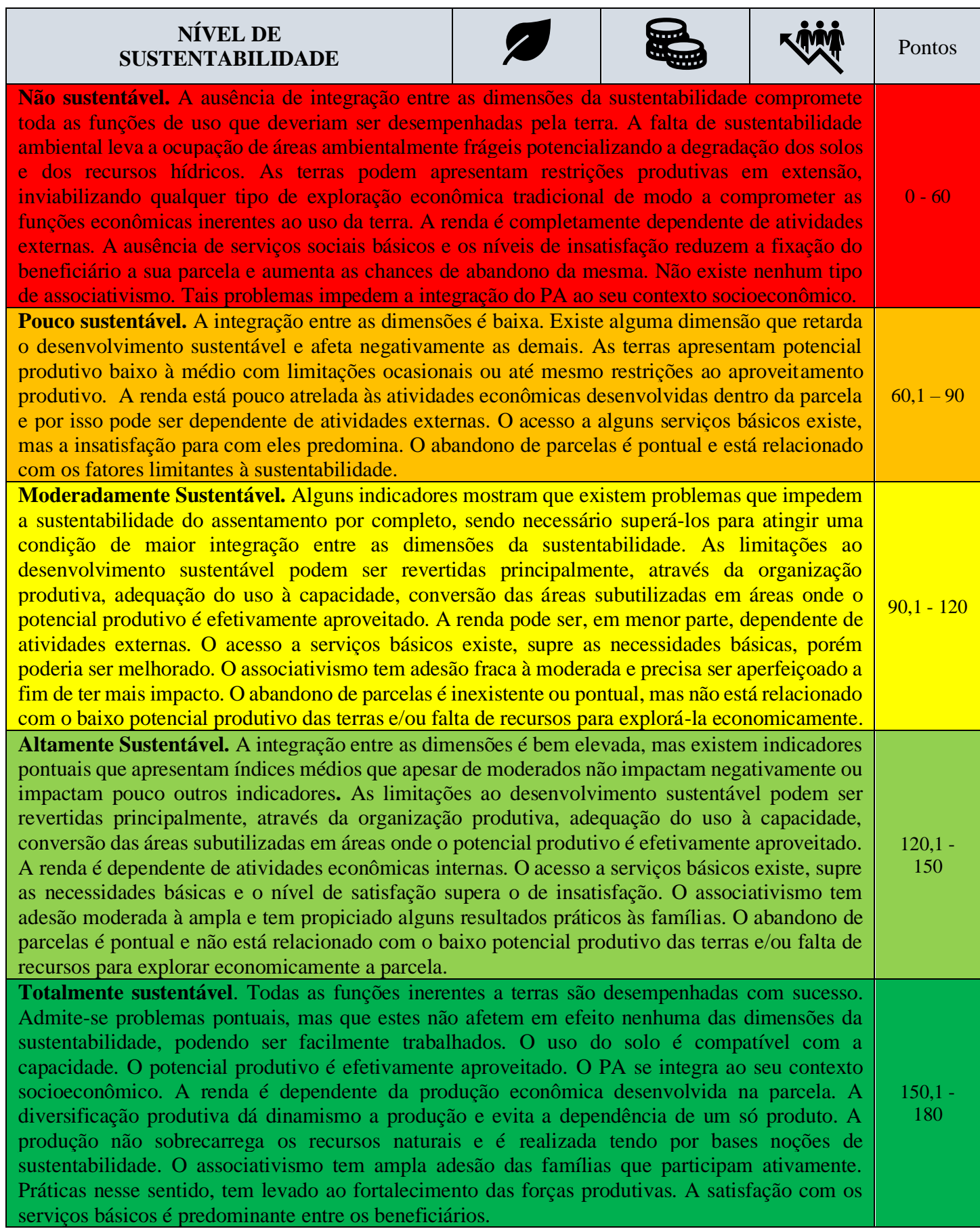

Fonte: Elaboração dos autores.

$\begin{array}{lllll}\text { Caminhos de Geografia } & \text { Uberlândia-MG } & \text { v. 23, n. } 85 & \text { fev./2022 } & \text { p. 157-176 Página } 173\end{array}$




\section{TESTE DA METODOLOGIA}

A título de exemplo, Santos (2018), em nível de mestrado, utilizou 16 dos 18 indicadores aqui sugeridos para avaliar a sustentabilidade em dois PAs de duas regiões bastante contrastadas no estado de Goiás, o PA Boa Esperança localizado no Sudeste goiano, microrregião considerada economicamente desenvolvida do Estado, e o PA Paraná localizado no Nordeste goiano, região mais pobre do Estado, expondo os resultados na forma de um gráfico do tipo radar (figura 7).

Figura 7. Avaliação comparada da sustentabilidade dos PAs Paraná e Boa Esperança (GO)

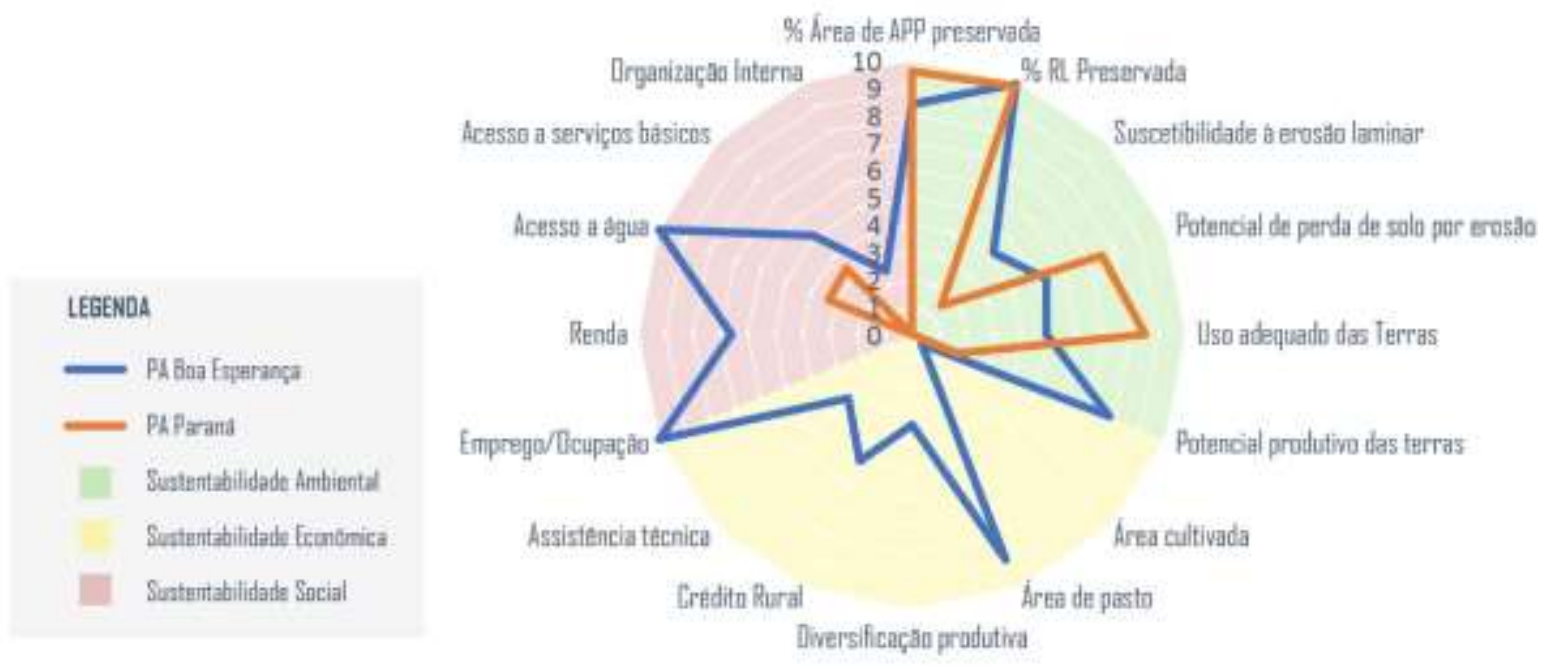

Fonte: Elaboração do autor.

Na Figura 7 pode-se identificar o comportamento das linhas internas de cada PA e o desempenho de todos os indicadores, na escala de 0 a 10, facilitando a identificação dos retardantes e dos impulsionadores do desenvolvimento sustentável. Pode-se observar que o PA Boa Esperança tem situação mais próxima da sustentabilidade, onde os problemas diagnosticados são a organização interna da comunidade, o difícil acesso a serviços básicos, a falta de assistência técnica e crédito rural. Já o PA Paraná, com exceção das áreas de APP e RL, praticamente todos os demais indicadores são baixos e vários são nulos, indicando insustentabilidade. A visualização em forma de gráfico de radar permitiu, além da identificação dos fatores impulsionadores e retardantes da sustentabilidade, a comparação entre os dois casos.

\section{CONSIDERAÇÕES FINAIS}

A avaliação da sustentabilidade dos PAs é imprescindível para o seu fortalecimento, uma vez que preza pela integração entre os diversos pilares representados pelas dimensões e indicadores que a compõem denominados de FUTs. Nesse sentido, o fortalecimento desses pilares indica a robustez e a pluriatividade do sistema ao observar que:

- as áreas rurais desempenham funções econômicas com sucesso ao integrarem a ao seu contexto socioeconômico local e regional;

- o assentamento sustentável de famílias promove conquistas para além da obtenção das terras, como ganhos em qualidade de vida, geração de renda e emprego;

- há condições de fixação das pessoas no campo de forma a evitar a saturação dos centros urbanos;

- o planejamento prévio do uso das terras visa o uso racional dos recursos bióticos e abióticos permitindo sua conservação e preservação (APP e RL);

$\begin{array}{lllll}\text { Caminhos de Geografia } & \text { Uberlândia-MG } & \text { v. 23, n. } 85 & \text { fev./2022 } & \text { p. 157-176 Página } 174\end{array}$


- há condições técnicas que permitem a exploração racional da terra sem que envolva as práticas da agricultura moderna, como a agroecologia.

O cumprimento desses quesitos, é claro, depende da vontade política para realizar avaliações diagnósticos voltadas à avaliação da sustentabilidade nos PAs já criados e, naqueles que virão, espera-se que sejam identificadas as possibilidades e os riscos a serem mitigados, buscando evitar a repetição de erros passados e permitindo a maximização dos resultados positivos. Nesse sentido, a metodologia adaptada da proposta de Pérez-Soba et al (2008), aqui exposta e testada para dois PAs do estado de Goiás, mostrou-se satisfatória por permitir reconhecer os indicadores retardantes e promotores do desenvolvimento sustentável, os quais corroboraram o status reconhecido das duas regiões focadas.

\section{REFERÊNCIAS}

ABRAMOVAY, R. O mundo desencantado dos assentamentos. pp. 313 - 322. In: MEDEIROS, L. et al. (Org.) Assentamentos rurais: uma visão multidisciplinar. São Paulo: Editora da Universidade Estadual Paulista, 1994.

ANJOS, F. S. Pluriatividade e desenvolvimento rural no Sul do Brasil. Caderno Ciência \& Tecnologia, Brasília, v. 20, n. 1, p. 11-44, jan. /abr., 2003.

BITTENCOURT, G. A. et al. Principais fatores que afetam o desenvolvimento dos assentamentos de reforma agrária no Brasil. Projeto de cooperação técnica INCRA/FAO, Brasília, 1999. EMBRAPA. Comparação de métodos de suporte à decisão para favorabilidade de terras para a agricultura familiar. Rio de Janeiro: Embrapa Solos, 2004.

FAO - FOOD AND AGRICULTURE ORGANIZATION OF THE UNITED NATIONS (FAO). The state of food and agriculture 1989. Roma: FAO, 1989. 173p.

FARIAS et al. Impacto dos assentamentos rurais no desmatamento da Amazônia. Mercator, Fortaleza, v. 17, 2018.

FERREIRA, B. Estratégias de intervenção do Estado em áreas de assentamento: as políticas de assentamento do Governo Federal. pp. 29 - 48. In: MEDEIROS, L. et al. (Org.) Assentamentos rurais: uma visão multidisciplinar. São Paulo: Editora da Universidade Estadual Paulista, 1994.

GRAZIANO NETO, Francisco. A (difícil) interpretação da realidade agrária. In: Schmidt, Benício Viero, Marinho, Danilo Nolasco C. \& Couto Rosa, Sueli L. (orgs.). Os Assentamentos de Reforma Agrária no Brasil. Brasília, Editora da UnB, 1998, p.153-169.

GUANZIROLI. Reforma Agrária: viabilidade econômica no contexto de uma política agrícola em transformação. Pp. 260-269. In: MEDEIROS, L. et al. (Org.) Assentamentos rurais: uma visão multidisciplinar. São Paulo: Editora da Universidade Estadual Paulista, 1994.

INCRA - INSTITUTO NACIONAL DE COLONIZAÇÃO E REFORMA AGRÁRIA. Informações gerais sobre os assentamentos de Reforma Agrária. Disponível em: < http://painel.incra.gov.br/sistemas/index.php>. Acesso em: 07 de jan. 2019.

IPAM - INSTITUTO DE PESQUISA AMBIENTAL DA AMAZÔNIA. Desmatamento nos assentamentos da Amazônia: histórico, tendências e oportunidades. IPAM: Brasília, 2016. 114p.

KAGEYAMA, A. Desenvolvimento rural: conceito e um exemplo de medida. In: XLII Congresso da Sociedade Brasileira de Economia e Sociologia Rural, 2004, Cuiabá. "Dinâmicas Setoriais e Desenvolvimento Regional", Anais... Cuiabá: 2004.

KAGEYAMA, A.; BERGAMASCO, S. M. P.; OLIVEIRA, J. A. Os assentamentos rurais no Censo Agropecuário de 2006. In: Simpósio sobre Reforma Agrária e Assentamentos Rurais, 4, 2010, Araraquara, SP. Anais...Araraquara: 2010.

KINSELLA, J. et al. Pluriactivity as a livelihood strategy in Irish farm households and its role in rural development. Sociologia Ruralis, v. 40 n.4, p.481-496, 2000.

LEITE JÚNIOR, C. B. et al. Indicadores social-econômico e ambiental em assentamentos de reforma agrária no Cerrado goiano. Campo - Território, v. 8, n.16, p. 342-378, 2013.

$\begin{array}{llllll}\text { Caminhos de Geografia } & \text { Uberlândia-MG } & \text { v. 23, n. } 85 & \text { fev./2022 } & \text { p. 157-176 Página } 175\end{array}$


LEPSCH, I.F. et al. Manual para levantamento utilitário do meio físico e classificação de terras no sistema de capacidade de uso. 4a Aproximação. 1. ed. Viçosa: Sociedade Brasileira de Ciência do Solo, 2015, 170p.

MALHEIROS, T. F. et al. Agenda 21 Nacional e indicadores de desenvolvimento sustentável: contexto brasileiro. Saúde Soc., São Paulo, v. 17, n. 1, p. 7-20, 2008.

MATTEI, F. L. A reforma agrária brasileira: evolução do número de famílias assentadas no período pós-redemocratização do país. Rio de Janeiro: Estud. Soc. E Agric. vol. 20. n. 1, 2012. pp. 301-325.

MEDEIROS, L. S. Luta por reforma agrária no Brasil contemporâneo: entre continuidades e novas questões. In: GRISA, Cátia; SCHNEIDER, Sérgio. (Org.). Políticas públicas de desenvolvimento rural no Brasil. 1ed. Porto Alegre: Editora da Universidade Federal do Rio do Sul, 2015, v. 1, p. 339360.

PÉREZ-SOBA, M.; et al. Land use functions: a multifunctionality approach to assess the impact of land use changes on land use sustainability. In: HELMING, K.; PÉREZ-SOBA, M.; TABBUSH, P. (Ed.). Sustainability impact assessment of land use changes. Berlin; New York: Springer, 2008. cap. 19, p. 375-404.

RATHMANN, R. et al. Diversificação produtiva e as possibilidades de desenvolvimento: Um estudo da fruticultura na Região da Campanha no RS. Revista de Economia e Sociologia Rural (Impresso), v. 46, p. $325-354,2008$.

RIBEIRO, D. D. Diversificação produtiva, geração e aumento de renda em assentamentos rurais a partir do milho crioulo. Ateliê Geográfico (UFG), v. 9, p. 109-127, 2015.

SACHS, I. Caminhos para o Desenvolvimento Sustentável. $3^{2}$ edição. Rio de Janeiro: Ed. Garamond, 2009.

SANTOS, J. G. R. Sustentabilidade de assentamentos rurais no estado de Goiás: avaliação comparada entre os assentamentos do nordeste e do sul goiano. 2018. 222 f. Dissertação (Mestrado em Geografia) - Universidade Federal de Goiás, Goiânia, 2018.

SMEETS, E.; WETERINGS, R. Environmental indicators: typology and overview. Copenhagen: European Environment Agency, 1999. (Technical report, n. 25).

SPAROVEK, G. A qualidade dos assentamentos de reforma agrária brasileira. São Paulo: Páginas \& Letras Editora e Gráfica, 2003.

SPAROVEK, G. Análise Territorial da produção nos assentamentos. Brasília: Ministério do Desenvolvimento Agrário: NEAD, 2005.

TURETTA, A. P. D.; COUTINHO, H. L. Funções de uso e indicadores de sustentabilidade: casos de expansão sucroalcooleira no Sudoeste de Goiás. In: Selma Simões de Castro, Luís Carlos Hernani, editores técnicos. (Org.). Solos frágeis: caracterização, manejo e sustentabilidade. 1ed.Brasília: Embrapa, 2015, v. 01, p. 326-344.

ZAMBERLAM, J. Reflexões sobre algumas estratégias para a viabilização econômica dos assentamentos. pp. 271 - 286. In: MEDEIROS, L. et al. (Org.) Assentamentos rurais: uma visão multidisciplinar. São Paulo: Editora da Universidade Estadual Paulista, 1994.

Recebido em: 23/09/2020

Aceito para publicação em: 02/11/2021 